\title{
Herding Behavior and Cryptocurrency: Market Asymmetries, Inter-Dependency and Intra-Dependency
}

\author{
Raja Nabeel-Ud-Din JALAL ${ }^{1}$, Massimo SARGIACOMO ${ }^{2}$, Najam Us SAHAR ${ }^{3}$, Um-E-Roman FAYYAZ ${ }^{4}$ \\ Received: May 05, 2020 Revised: May 17, 2020 Accepted: June 10, 2020
}

\begin{abstract}
The study investigates herding behavior in cryptocurrencies in different situations. This study employs daily returns of major cryptocurrencies listed in CCI30 index and sub-major cryptocurrencies and major stock returns listed in Dow-Jones Industrial Average Index, from 2015 to 2018. Quantile regression method is employed to test the herding effect in market asymmetries, inter-dependency and intra-dependency cases. Findings confirm the presence of herding in cryptocurrency in upper quantiles in bullish and high volatility periods because of overexcitement among investors, which lead to high volume trading. Major cryptocurrencies cause herding in sub-major cryptocurrencies, but it is a unidirectional relation. However, no intra-dependency effect among cryptocurrencies and equity market is observed. Results indicate that in the CKK model herding exists at upper quantile in market that may be due when the market is moving fast, continuously trading, and bullish trend are prevailing. Further analysis confirms this narrative as, at upper quantile, the beta of bullish regime is negative and significant, meaning the main source of market herding is a bullish trend in investment, which increases market turbulence and gives investors opportunity to herd. Also, we found that herding in cryptocurrencies exits in high volatility periods, but this herding mostly depends on market activity, not market movement.
\end{abstract}

Keywords: Herding Behavior, Cryptocurrencies, Quantile Regression, Market Asymmetries, Inter-Dependency, Intra-Dependency

JEL Classification Code: B23,G2,G4.

\section{Introduction}

With time, financial markets have become mature and regularized (Moloney, 2010). The standard finance theories

${ }^{1}$ First Author and Corresponding Author. PhD Researcher, Dipartmento di Economia Aziendale, Università degli Studi "G.d'A" ChietiPescara, Italy [Postal Address: Viale Pindaro 42, 65127 Pescara, Italy] Email: nabeel.jalal@unich.it

2Ordinary Professor of Accounting, Dipartmento di Economia Aziendale, Università degli Studi "G.d'A" Chieti-Pescara, Italy. Email: msargiacomo@unich.it

${ }^{3}$ Assistant Professor of Finance, FMS, Riphah International University, Islamabad, Pakistan.

Email: Najam.sahar@riphah.edu.pk

${ }^{4} \mathrm{PhD}$ Researcher, Dipartmento di Economia Aziendale, Università degli Studi "G.d'A" Chieti-Pescara, Italy.

Email: umeroman.fayyaz@unich.it

(c) Copyright: The Author(s)

This is an Open Access article distributed under the terms of the Creative Commons Attribution Non-Commercial License (http://Creativecommons.org/licenses/by-nc/4.0/) which permits unrestricted noncommercial use, distribution, and reproduction in any medium, provided the original work is properly cited. posit that any investment made by the investor follows the rationality and fundamental, but are unable to explain the volatility in high speculative markets (Javaira \& Hassan, 2015). The investment and behavioral finance studies focus more on investor behavior and how it influences the market return rather than relying on market fundamentals. Herding behavior is considered as one factor, as it works by neglecting the market fundamentals and denies the existence of an efficient market hypothesis (Fama, 1970).

Bitcoin entered the market at a time when blockchain networks started to gain attention (Nakamoto, 2008). Initially, blockchain is designed for the payment system. Enterprises begin to recognize it as a payment system as consumeroriented transactions frequency increased in the past few years (Bouri, Gupta, \& Roubaud, 2018; Bouri, Molnár, Azzi, Roubaud, \& Hagfors, 2017; Dyhrberg, 2016a, 2016b; Polasik, Piotrowska, Wisniewski, Kotkowski, \& Lightfoot, 2015). But, the users of bitcoin have found more exciting benefits for other purposes. From an investment perspective, this digital currency has an impressive feature and has a lot of potentials to offer, which it has already provided in recent years. 
The success of bitcoin and cryptocurrencies has become a new asset in which people invest to get maximum returns. Due to high volatility and growth in its markets capitalization, the dynamics of modern cryptocurrencies have started to gain traction in the literature, and their determinants and associations are being studied by researchers (Ciaian, Rajcaniova, \& Kancs, 2016; Li \& Wang, 2017; Panagiotidis, Stengos, \& Vravosinos, 2018). Cryptocurrencies are highly speculative, and it is volatile behavior that makes them difficult to predict rather than the influence of fundamentals sentiments. Initially, researchers have started to discuss the factors and components of cryptocurrencies and how they are linked with the present financial system (Cheah \& Fry, 2015; Katsiampa, 2017). But, from the past two years, scholars have started to critically evaluate bitcoin and other cryptocurrencies in terms of their efficiency, portfolio management, and risk diversification (Cheah \& Fry, 2015; Corbet, Lucey, \& Yarovaya, 2018; Fry, 2018; Nadarajah \& Chu, 2017; Urquhart, 2016; Vidal-Tomás, Ibáñez, \& Farinós, 2018). There are limited studies that focus on interdependencies (Ciaian et al., 2016), and association (Chu, Chan, Nadarajah, \& Osterrieder, 2017; Gandal \& Halaburda, 2016; Osterrieder \& Lorenz, 2017). Similarly, Bouri et al. (2018) studied herding behavior in the crypto market.

As the market is still in the development stage, the legality factor associated is still widely focused on and is debatable. There are many deadlocks for cryptocurrencies (Nadarajah \& Chu, 2017), which are yet to be opened, but still, the crypto market is witnessing growth. This growth may be due to behavioral biases, not the fundamentals as the fundamentalist approach denies cryptocurrencies are recording a stable growth based on its recognition, different working pattern, and high volatility. In the behavioral finance spectrum, the growth and massive trading in cryptocurrencies may be due to the irrational behavior of investors. Also, scarce information and the sense of missing out on the opportunity of profit-making is pushing them to invest in massive proportion and causing herding as well as a market crash. The decision made by investors based on irrationality and the herding environment relies on market movement and behavior, not on rational trends. We observe the herding behavior in these specific conditions. Section 2 of the paper reviews the existing literature on herding and how it is working in the market. Section 3 presents the methodology and Section 4 explains the outcomes and offers conclusions in light of the empirical investigation.

\section{Literature Review}

Avery and Zemsky (1998) stated that the herding concepts visualize the animal spirit driving the market behavior as the participants mimic the trading behavior of each other by neglecting the available information to them.
The herding arises from the informational difference and poor accessibility, which create an upward trend in market volatility (Bikhchandani \& Sharma, 2001; Tu \& Liao, 2020). The literature indicates that the debate on herding behavior covers two narratives, i.e., psychological and rational narratives. This also leads to studying personality and investor behavioral factors in business (Jalal, Zeb \& Fayyaz, 2019) and investment domains. The first narrative on herding behavior emphasizes investor psychology, his or her thinking, and behaving pattern (Devenow \& Welch, 1996). Personality factors influence an investor trading behavior, for example, if he or she is neurotic, so they will passively follow the significant trend in the market. Furthermore, paying attention to uncertain scenarios instead of trusting the information available, investors try to imitate the behavior of other market participants, which creates a "sheep flock trend." Neuroeconomics perspective of herding strengthens this psychological herding argument, as individuals subconsciously adopt the behavior of fellow individuals rather than make a rational response (Devenow \& Welch, 1996; Pretcher, 2001). Furthermore, one of the emotional or sentimental factors influencing herding behavior under the behavioral paradigm is the reputation factor. The fund manager sets a benchmark for his fellow market manager and imitates his investment pattern, which is not socially and rationally accurate, but is rationally valid according to managers (Zweibel, 1995; Prendergast \& Stole, 1996; Grahm, 1999).

Whereas, rational herding narrative defines herding, linking the emotional strands with rationality in decisionmaking. The logical grounds for this narrative moves around supply elasticity, which is assessed as an investment opportunity for investors because securities are available at the same price for all market investors (Bikchandani et al. 1992; Banerjee, 1992). Under these circumstances, Fama and French (1992) markets will have the stable form of market efficiency to some extent as only public information will be available to all investors, and private information will be inaccessible to them. The inaccessibility of private information leads investors to follow their rationales, and investor behavior will state private information. Apart from the theoretical justification related to herding sources, the empirical literature focuses on herding in two broad aspects, i.e., professional and overall market. The professional points of herding focus on market participants like fund managers and financial analysts as they are working within the market and have maximum information accessibility (Caglayan, Celiker, \& Sonaer, 2018; Jiang and Verardo, 2018; Wermers, 1999; Welch, 2000, Clement \& Tse 2005). The second aspect focuses on overall market herding analyzed by using measures of cross-sectional dispersion of market asset returns (Christie \& Huang, 2005; Blasco \& Ferreruela, 2008; Chiang \& Zheng, 2010; Yao et al., 2013; Lee, 2017). 
The important work of Christie and Huang (1995) is considered classical and vital to understand the herding behavior empirically. They incorporated cross-sectional standard deviation returns, commonly termed as CSSD, and reported the existence of herding in the market at two levels, i.e., overall market level and industrial level. Later, Chang et al. (2000) criticized the technique developed by Christie and Huang (1995) by stating that, in the presence of herding, the average dispersion among asset return and the market return is low. Thus, the herding behavior detected through this method cannot be declared conclusive. Further, Change et al. (2000) also proposed a modified model to measure herding behavior. They used cross-sectional absolute deviation (CASD) of market returns and tested it in five major markets (US, Hong-Kong, Japan, Taiwan, and South Korea). They reported no existence of herding behavior in the US and Hong-Kong markets, existence of herding in Japan, Taiwan, and South Korea. Also, another modified model focused on a cross-section of the factor of sensitivity and reported low herding in a crisis period as compared to a regular period.

The application of core finance theories and their modified versions (keeping in mind the crypto market) is helping in understanding the behavior of cryptocurrencies. More than a payment instrument, cryptocurrencies are used for trading and investment purposes. Lack of recognition (Nadarajah $\& \mathrm{Chu}, 2017)$ decreases the information available in the market and creates irrationality in the market. Under these circumstances, the decisions are based on market behavior and movement, not on rational behavior. This irrationality creates hype in investment if the market observes move upward, which causes herding and lead to a market crash (Ajaz \& Kumar, 2018).

The literature highlights that, when investor decision is not based on rationality, investors consider market moving on the behavioral pattern and blindly follow available information (Zwiebel Pretcher, 2011). As previously stated, herding focused on the equity market (Blasco \& Ferreruela, 2008; Chiang \& Zheng, 2010; Yao et al., 2013; Lee, 2017). This study tries to apply the same method on cryptocurrency because of common traits to equity market like volatility clustering, bubbles, and inefficiency (Dwyer, 2015; Dyhrberg, 2016a, 2016b; Urqhart, 2016).

\section{Methodology}

We divided our study into three parts. Firstly, to check the existence of herding behavior under market asymmetries. Secondly, to analyze the interrelation among major cryptocurrencies and sub-major cryptocurrencies.Thirdly, to observe intra-relation in the perspective of herding in the equity market and its influence in cryptocurrencies.

Herding behavior is analyzed by creating a market portfolio by selecting a specified group of securities or assets.
Keeping in mind the objective of our study, we have used the CCI30 index, which is based on 30 major cryptocurrencies ranked and index on the basis of market capitalization over a period of time. Further, we have selected six major currencies (bitcoin, litecoinethereum, ripple, nem and dash) from the CCI30 index to analyze the herding behavior based on their market capitalization as well as the volatility behavior and interrelation. With the selection of the CCI30 index, we limited our analysis, beginning on $1 / 1 / 2015$, because the index was available from that year, and end on 15/1/2019. Daily data are used in this study. The descriptive statistics in Table 1 indicates that all cryptocurrencies, except bitcoin, are positively skewed and non-normally distributed. The market proxy is represented by CCI30 and is positively skewed and non-normally distributed.

Cross-sectional stand deviation of returns (CSSD) and cross-sectional mean absolute deviation (CSAD) are widely used along with beta herding to analyze the herding behavior in the specific market, but CSSD and CSAD are more closely related. The CSSD method of herding detection was designed by Christie and Huang (1995). It is defined as:

$$
C S S D=\sqrt{\frac{\sum_{i=1}^{n}\left(R_{i, t}-\bar{R}\right)^{2}}{n-1}}
$$

Where,

$\mathrm{R}_{\mathrm{i}, \mathrm{t}}=$ "observed return on asset $\mathrm{i}$ ", $\bar{R}=$ "average market return of the asset n".

Christie and Huang (1995) stated that in the presence of herding the average dispersion among asset returns and market returns would be low, meaning investors will make a similar decision or on the preference of major market behavior rather than relying on the individual. As the outliers related to CSSD have a direct impact, so the herding behavior detected through this method cannot be declared conclusive. Chang et al. (2000) tried to address this issue by

Table 1: Descriptive Statistics

\begin{tabular}{|l|c|c|c|c|c|}
\hline & Mean & $\begin{array}{c}\text { Std. } \\
\text { Dev. }\end{array}$ & Skewness & Kurtosis & $\begin{array}{c}\text { Jarque- } \\
\text { Bera }\end{array}$ \\
\hline BTC & 0.0019 & 0.038 & -0.2550 & 8.063 & $1495.93^{*}$ \\
\hline DAS & 0.0020 & 0.066 & 0.951 & 15.071 & $8624.574^{* *}$ \\
\hline ETH & 0.0026 & 0.072 & 3.044 & 43.890 & $98700.32^{* *}$ \\
\hline LITE & 0.0028 & 0.119 & 3.558 & 49.431 & $127426.7^{* *}$ \\
\hline NEM & 0.0039 & 0.087 & 1.899 & 19.760 & $17055.23^{* *}$ \\
\hline XRP & 0.0026 & 0.080 & 2.072 & 19.464 & $16647.70^{* *}$ \\
\hline CASD & 0.0479 & 0.036 & 3.009 & 17.986 & $15063.20^{* *}$ \\
\hline RM & 0.0025 & 0.045 & -1.424 & 17.449 & $12526.10^{* *}$ \\
\hline
\end{tabular}


proposing a modified and better model of herding detection. It is defined as

$$
\operatorname{CSAD}_{t}=\frac{1}{N} \sum_{i=1}^{N}\left|R_{i, t}-R_{m, t}\right|
$$

Where,

$\mathrm{R}_{\mathrm{i}, \mathrm{t}}=$ "Return of ith asset", $\mathrm{R}_{\mathrm{m}, \mathrm{t}}=$ "Return of market portfolio".

Chang et al. (2000) proposed a regression model which is also known as the CKK model to detect herding behavior. The equation iii is as follow

$$
C A S D_{t}=\beta_{0}+\beta_{1}\left|R_{m, t}\right|+\beta_{2} R_{m, t}^{2}+\varepsilon_{t}
$$

Where, $\mathrm{R}_{\mathrm{i}, \mathrm{t}}=$ "Return ofith asset", $\mathrm{R}_{\mathrm{m}, \mathrm{t}}=$ "Return of market portfolio".

This model follows the asset pricing theory assumption as cryptocurrencies are also used for investment and diversification purpose as cited in the literature. The model explains a linear relationship between CSAD and market return. Herding exists only in the case when the investor makes a decision based on market behavior and cumulative decision pattern during uncertain conditions. The decision made under these conditions lead towards high correlation among return of securities and simultaneously dispersion in return will decrease. Thus, this explains the non-linearity likeness in the relationship, which further captured squared market return and if it is negative and significant, which defines deviation from linear asset pricing model, meaning the presence of herding behavior.

Further, the primaryobjective of this study is to try to understand the herding behavior during asymmetries, which are addressed as market conditions or trends and volatility. To analyze the herding behavior under asymmetric conditions, i.e., bullish and bearish trends, we have introduced a dummy variable as $D^{U_{m c}}$. When there is a bullish trend the returns will be greater than zero, i.e., $D^{U_{m c}}=1$, if $\mathrm{R}_{\mathrm{m}, \mathrm{t}}>0$ and under bearish trend $D^{U_{m c}}=0$, if $\mathrm{R}_{\mathrm{m}, \mathrm{t}}<0$, where $\mathrm{R}_{\mathrm{m}, \mathrm{t}}$ is average market return. The equation "iv" capture herding behavior under asymmetric periods of bullish and bearish market trends.

$$
\begin{aligned}
C A S D_{t}= & \beta_{0}+\beta_{1}\left|R_{m, t}\right| * D^{U_{\text {mac }}}+\beta_{2}\left(1-D^{U_{\text {mac }}}\right) *\left|R_{m, t}\right| \\
& +\beta_{3} R_{m, t}^{2} * D^{U_{m c}}+\beta_{4}\left(1-D^{U_{\text {mac }}}\right) * R_{m, t}^{2} \\
& +\varepsilon_{t}
\end{aligned}
$$

Where, $\beta_{3}$ and $\beta_{4}$ defining the asymmetries.

If $\beta_{3}$ is significant negative means herding exist under bullish trend in market. Also, if $\beta_{4}$ is significant and negative herding exist under bearish trend in market. Insignificant means no detection of herding in specific period. However, if the results are positive anti-herding may exit.

To understand the role of volatility as market asymmetry on herding behavior in cryptocurrencies, we divided the volatility period into two streams periods of high volatility and period of low volatility, and tried to detect herding in this type of market asymmetry. Squared market return is taken as proxy of volatility and moving averages is used to generate the crypto-market volatility. We generated a dummy $\boldsymbol{D}^{V_{\text {ma }}}$ stating low and high volatility expressed by " 1 " and " 0 ". We used squared market return to measure the $\boldsymbol{D}^{V_{m a}}$ dummy, i.e., $\boldsymbol{D}^{V_{m a}}=1$, if $\mathrm{V}_{\mathrm{m}, \mathrm{t}}>R_{m, t}^{2}$. And $\boldsymbol{D}^{V_{m a}}=0$, if $\boldsymbol{D}^{V_{m a}}=1, \mathrm{~V}_{\mathrm{m}, \mathrm{t}}<R_{m, t}^{2}$. Keeping this in mind, the CKK model variant equation $v$ is established.

$$
\begin{aligned}
C A S D_{t}= & \beta_{0}+\beta_{1}\left|R_{m, t}\right| * D^{V_{m a}}+\beta_{2}\left(1-D^{V_{m a}}\right) *\left|R_{m, t}\right| \\
& +\beta_{3} R_{m, t}^{2} * D^{V_{m a}}+\beta_{4}\left(1-D^{V_{m a}}\right) * R_{m, t}^{2}+\varepsilon_{t}
\end{aligned}
$$

\section{Where $\beta_{3}$ and $\beta_{4}$ explains the voltality period}

If $\beta_{3}$ is significant and negative it means herding exists during high volatility market. Also, if $\beta_{4}$ is significant and negative herding exists during low volatility in the market. Insignificant means no detection of herding in a specific period. However, if the results are positive anti-herding exit.

Further, to study interdependencies among cryptocurrencies and intra-dependencies among cryptocurrency and equity market, we modified the approach used by Chiang and Zheng (2010). For interdependency among cryptocurrencies, we divided the crypto market into two groups similar to the approach by Vidal-Tomás et al. (2018). We selected 16 cryptocurrencies grouped as sub-major categoriesto analyze the role of major cryptocurrencies market (study the main sample) on herding in sub-major cryptocurrencies market as in equation vi. $\operatorname{CASD}_{s m, t},\left|R_{s m, t}\right| * D^{U_{s t}}, \beta_{2}\left(1-D^{U_{s m}}\right) *\left|R_{s m, t}\right|, R_{s m, t}^{2} * D^{U_{s m}},\left(1-D^{U_{s m}}\right) * R_{s m, t}^{2}$ define sub-major market currencies herding.

$$
\begin{aligned}
C A S D_{s m, t} & =\beta_{0}+\beta_{1}\left|R_{s m, t}\right| * D^{U_{s b}}+\beta_{2}\left(1-D^{U_{s m}}\right) *\left|R_{s m, t}\right| \\
& +\beta_{3} R_{s m, t}^{2} * D^{U_{s m}}+\beta_{4}\left(1-D^{U_{s m}}\right) * R_{s m, t}^{2} \\
& +\beta_{5} C S A D_{m j, t}+\beta_{6} R_{m j, t}^{2} * D^{U_{m j}} \\
& +\beta_{7}\left(1-D^{U_{m j}}\right) * R_{m j, t}^{2} \\
& +\varepsilon_{t}
\end{aligned}
$$

Further, we analyzed the intra-dependency feature by checking the influence of equity market herding in crypto market herding as in equation vii. As the crypto 
market and equity market have similar common traits like volatility clustering, bubbles, and inefficiency (Dwyer, 2015; Dyhrberg, 2016a, 2016b; Urqhart, 2016). As $\left|R_{c m, t}\right| * D^{U_{c m c}},\left(1-D^{U_{c m c}}\right) *\left|R_{c m, t}\right|, R_{c m, t}^{2} * D^{U_{c m c}},\left(1-D^{U_{c m c}}\right) * R_{c m, t}^{2}$ referred to crypto market and $C S A D_{e m, t}, R_{e m, t}^{2} * D^{U_{e m}}$ $\left(1-D^{U_{m m}}\right) * R_{e m, t}^{2}$ states equity market.

$$
\begin{aligned}
& C A S D_{c m, t}=\beta_{0}+\beta_{1}\left|R_{c m, t}\right| * D^{U_{c m c}}+\beta_{2}\left(1-D^{U_{c m c}}\right) *\left|R_{c m, t}\right| \\
& +\beta_{3} R_{c m, t}^{2} * D^{U_{c m c}}+\beta_{4}\left(1-D^{U_{c m c}}\right) * R_{c m, t}^{2}+\beta_{5} C S A D_{e m, t} \\
& +\beta_{6} R_{e m, t}^{2} * D^{U_{c m}}+\beta_{7}\left(1-D^{U_{c m}}\right) * R_{e m, t}^{2}+\varepsilon_{t}
\end{aligned}
$$

\section{Results}

From the regression results at different quantile, we try to understand the direction of fluctuations. It can be observed in Table 2 that $\beta_{2}$ in upper quantile $(\tau=.90)$ is negative and statistically significant, which confirms the presence of herding in upper quantile, except $=0.75$. Whereas, in lower quantiles $(\tau=0.10,0.25)$ median quantile $(0.50)$ is negative, but insignificant. We can conclude that there is the presence of herding in upper quantiles because of the dispersion of returns.

The equation (iv) captures the herding effect during this specific market asymmetry. The results reported in Table 3 provide an insight whether herding exists in bullish or bearish regime. $\beta_{3}$ and $\beta_{4}$ define the market asymmetries. If $\beta_{3}$ is significant and negative, it means herding exists under bullish trend in market. Also, if is significant and negative, herding exists under bearish trend in market. Insignificant means no detection of herding in the specific period. However, if the results are positive anti-herding exits.

The traces of herding were not found in lower quantile when the market is experiencing bullish trend as there is low turbulence, while market at $\tau=.10$ and 0.25 . Also, in upper

\begin{tabular}{|c|c|c|c|c|c|}
\hline \multicolumn{6}{|c|}{$C A S D_{t}=\beta_{0}+\beta_{1}\left|R_{(m, t)}\right|+\beta_{2} R_{(m, t)}^{2}+\varepsilon_{t}$} \\
\hline & $\tau=\mathbf{0 . 1}$ & $\tau=0.25$ & $\tau=0.50$ & $\tau=0.75$ & $\tau=0.90$ \\
\hline $\boldsymbol{\beta}_{0}$ & $.0107^{* * *}$ & $.0168^{* * *}$ & $.0250^{* * *}$ & $.0389^{* * *}$ & $.0564^{* * *}$ \\
\hline$\beta_{1}$ & $.2247^{* * *}$ & $.2993^{\star \star *}$ & $.4481^{\star \star \star *}$ & $.5393^{\star \star \star}$ & $.8622^{\star \star \star}$ \\
\hline$\beta_{2}$ & .0017 & -.1164 & -.1454 & .2912 & $-.7312^{* *}$ \\
\hline $\bar{R}$ & .060 & .081 & .108 & .122 & .145 \\
\hline
\end{tabular}
quantiles we found herding presence as $\beta_{3}$ is negative and

Table 2: Regression results at different quantile significant, while market is bullish at $\tau=0.75$ and 0.90 . We can conclude that herding exist at high turbulence at upper quantiles. Moreover, when market is at median it observes constant increasing and decreasing turbulence, and results shows that herding while in bullish market regime exist in cryptocurrencies. This confirms that the behavior of investor is not rational and their decision-making tendency is driven by their enthusiasm and reactions. They make purchase decisions when the market shows a slight increase or major increase and when the market movement goes downward; it creates panic among investors, and they start to sell their assets. Moreover, the autoregressive term was included during analysis.

Further, we examine the herding behavior in high and low volatility period (see Table 4 ). We generated a dummy $\boldsymbol{D}^{V_{m a}}$ stating low and high volatility expressed by "1" and "0"i.e. $\boldsymbol{D}^{V_{m a}}=1$, if $\mathrm{V}_{\mathrm{m}, \mathrm{t}}>$ And $\boldsymbol{D}^{V_{\text {ma }}}=0$, if $\boldsymbol{D}^{V_{m a}}=1$, $\mathrm{V}_{\mathrm{m}, \mathrm{t}}<R_{m, t}^{2}$. Keeping this in mind, the CKK model variant equation $\mathrm{v}$ is established. To calculate the volatility we used

\begin{tabular}{|c|c|c|c|c|c|}
\hline \multicolumn{6}{|c|}{$\begin{aligned} C A S D_{t} & =\beta_{0}+\beta_{1}\left|R_{(m, t)}\right|^{*} D^{\left(v_{m a}\right)}+\beta_{2}\left(1-D^{\left(v_{m a}\right)}\right)^{*}\left|R_{(m, t)}\right| \\
& +\beta_{3} R_{(m, t)}^{2} D^{\left(v_{m a}\right) *}+\beta_{4}\left(1-D^{\left(v_{m a}\right)}\right)^{*} R_{(m, t)}^{2}+\varepsilon_{t}\end{aligned}$} \\
\hline & $\tau=0.1$ & $\tau=0.25$ & $\tau=0.50$ & $\tau=0.75$ & $\tau=0.90$ \\
\hline$\beta_{0}$ & $0.0108^{* * *}$ & $.0106^{\star \star *}$ & $.0246^{* * *}$ & $.0365^{\star \star \star}$ & $.0543^{\star \star \star}$ \\
\hline$\beta_{1}$ & $.2014^{* *}$ & $.2805^{\star *}$ & $.5055^{* * *}$ & $.9017^{\star *}$ & $1.199^{*}$ \\
\hline$\beta_{2}$ & $.2033^{* *}$ & $.2300^{* * *}$ & $.4156^{* * *}$ & $.5152^{\star * \star}$ & $.7046^{* * *}$ \\
\hline$\beta_{3}$ & 1.1768 & 1.844 & .9165 & $-3.6723^{* *}$ & 1.2018 \\
\hline$\beta_{4}$ & .01004 & $.3997^{\star * *}$ & -.0685 & .3764 & .1580 \\
\hline $\bar{R}$ & .060 & .085 & .110 & .125 & .159 \\
\hline
\end{tabular}
the moving average of squared market return as proxy.

Table 4:Herding behavior in high and low volatility period

\begin{tabular}{|c|c|c|c|c|c|}
\hline & $\tau=0.1$ & $\tau=0.25$ & $\tau=0.50$ & $\tau=0.75$ & $\tau=0.90$ \\
\hline$\beta_{0}$ & $.0074^{*+x+x}$ & $.0115^{* * * *}$ & $.0145^{\text {tat }}$ & $.0191^{* * * t}$ & $.03011^{*+* t}$ \\
\hline$\beta_{1}$ & $.2447^{* * * x}$ & $.2880^{*+* t}$ & $.3830^{4 * t *}$ & $.4804^{* * * *}$ & $.7269^{* *+*}$ \\
\hline$\beta_{2}$ & .0682 & $.1097^{* *}$ & $.1629^{*+*}$ & $-.01972^{* * * *}$ & $.3530^{* * * *}$ \\
\hline$\beta_{3}$ & $1.156^{* *+*}$ & $.9829^{*}$ & $.5515^{* * *}$ & $-.0708^{* * * t}$ & $-2.248^{* *}$ \\
\hline$\beta_{4}$ & .5407 & $.6446^{* * *}$ & $.4508^{\text {t*t }}$ & $.8559^{*+* x}$ & .2225 \\
\hline $\bar{R}$ & .117 & .149 & .203 & .252 & .290 \\
\hline
\end{tabular}

Table 3: Herding effect during the specific market asymmetry 
Results in Table 4 providean insight about the herding presence in high and low volatility period in crypto currency market. The results state that the lower quantile $\beta_{4}$ is statistically significant and positive at $\tau=0.25$ whereas the rest of quantilesshows no significant relationship. It can be inferred there is no herding during low volatility period. However, in upper tail it was found that $\beta_{3}$ is statistically significant and negative, confirming the existence of herding behavior at high volatility in market only at $\tau=0.75$. Furthermore, the interdependencies within market can influence the herding behavior (Chiang \& Zheng, 2010). With this objective we analyzed the interdependencies among major cryptocurrencies and sub-major cryptocurrencies defined in the methodology. The first part of the equation provides the information on herding presence in submajor cryptocurrencies and the second part provides the information about the existence of herding because of major currencies.

In light of results in Table 5, there is no presence of herding in sub-major cryptocurrencies during high turbulence period as $\beta_{3}$ in all quantiles except $=0.90$ is insignificant and, at $\tau=0.90$, it is significant, but positive which confirms no herding at all quantiles. However, $\beta_{4}$ in lower tail at $\tau=0.10$ is statistically significant and negative, meaning herding exists at lower quantile when market is slow. But there is no trace of herding while at $\tau=0.25$ and at median. Whereas, herding is detected at upper quantile when the market is getting slower while at $\tau=0.75,0.90$.

Table 5: Herding in sub-major cryptocurrencies during high turbulence period

\begin{tabular}{|c|c|c|c|c|c|}
\hline \multicolumn{6}{|c|}{$\begin{array}{l}C A S D_{s m, t}=\beta_{0}+\beta_{1}\left|R_{s m, t}\right| * D^{U_{s b}}+\beta_{2}(1-1 \\
+\beta_{3} R_{s m, t}^{2} * D^{U_{s m}}+\beta_{4}\left(1-D^{U_{s m}}\right) * R_{s m, t}^{2}+\beta_{5} \\
+\beta_{6} R_{m j, t}^{2} * D^{U_{m j}}+\beta_{7}\left(1-D^{U_{m j}}\right) * R_{m j, t}^{2}+\varepsilon_{t}\end{array}$} \\
\hline & $\tau=0.1$ & $\tau=0.25$ & $\tau=0.50$ & $\tau=0.75$ & $\tau=0.90$ \\
\hline$\beta_{0}$ & $.0215^{\star * *}$ & $.02633^{* * *}$ & $.03200^{* * *}$ & $.0377^{\star * *}$ & $.0445^{* * *}$ \\
\hline$\beta_{1}$ & $.2150^{* *}$ & $.2047^{* *}$ & $.4062^{* * *}$ & $.5015^{\star \star *}$ & $.6360^{* * *}$ \\
\hline$\beta_{2}$ & $.1631^{* * *}$ & $.1896^{* * *}$ & $.2370^{* * *}$ & $.3241^{* * *}$ & $.5761^{* * *}$ \\
\hline$\beta_{3}$ & .2582 & 1.0436 & .8296 & .8079 & $1.7806^{* * *}$ \\
\hline$\beta_{4}$ & $.5533^{* * *}$ & -.2219 & -.0068 & $-.4099^{*}$ & $-1.510^{\star * *}$ \\
\hline$\beta_{5}$ & .01903 & $.0638^{* *}$ & $.1307^{* * *}$ & $.2151^{* * *}$ & $.2970^{* * *}$ \\
\hline$\beta_{6}$ & .0042 & -.1086 & $-.6200^{* *}$ & $-.9147^{* * *}$ & $-1.240^{\star * *}$ \\
\hline$\beta_{7}$ & .3520 & .0783 & $-.1455^{*}$ & $-.2552^{\star * *}$ & $-.2497^{* * *}$ \\
\hline $\bar{R}$ & .075 & .0927 & .154 & .223 & .2873 \\
\hline
\end{tabular}

Moreover, no influence on major markets were detected at lower quantile, meaning that at this point they are not the driving force in the market. However, at upper quantile and at median $\beta_{6}$ and $\beta_{7}$ there are significant, meaning that major cryptocurrencies are acting as the driving force in the market and create movement. According to Dwyer (2015), Dyhrberg (2016a, 2016b) and Urqhart (2016) cryptocurrency markets and equity markets share similar traits as both have the volatility clustering, bubbles and inefficiency. Keeping in mind these, we tested to check whether equity market can influence crypto market herding and the results are reported in Table 6.

The results state that $\beta_{3}$ and $\beta_{4}$ are significant and negative at all major quantiles, meaning cryptocurrency defines their own herding phenomenon. Whereas, $\beta_{6}$ and $\beta_{7}$ shows that cryptocurrency market herding is not determined by equity market though they share same features, but the dynamics are different as equity market is highly regulated as compared to crypto market (Moloney, 2010; Nadarajah \& Chu, 2017). Further, we tried to check whether the coefficients values are different in all quantiles. For that, we tested the slope of equality and the chi-square value, which were found to be significant confirming that the herding behavior varies among different quantiles.

\section{Conclusion}

We tried to test the existence of herding behavior by employing the quantile regression analysis. To analyze the

Table 6: Influence of equity market herding in crypto market

\begin{tabular}{|c|c|c|c|c|c|}
\hline \multicolumn{6}{|c|}{$\begin{array}{l}C C A S D_{c m, t}=\beta_{0}+\beta_{1}\left|R_{c m, t}\right| * D^{U_{c m c}}+\beta_{2}(1- \\
+\beta_{3} R_{c m, t}^{2} * D^{U_{c m c}}+\beta_{4}\left(1-D^{U_{c m c}}\right) * R_{c m, t}^{2}+\beta_{5} \\
+\beta_{6} R_{e m, t}^{2} * D^{U_{e m}}+\beta_{7}\left(1-D^{U_{e m}}\right) * R_{e m, t}^{2}+\varepsilon_{t}\end{array}$} \\
\hline & $\tau=0.1$ & $\tau=0.25$ & $\tau=0.50$ & $\tau=0.75$ & $\tau=0.90$ \\
\hline$\beta_{0}$ & $-1.07 E-5^{* * *}$ & $-4.10 \mathrm{E}-23$ & $-3.07 E-07$ & $.0021^{* * *}$ & $.00521^{* * *}$ \\
\hline$\beta_{1}$ & $.603^{* * *}$ & .8590 & $1.0699^{* * *}$ & $.9786^{* * *}$ & $1.04^{* * *}$ \\
\hline$\beta_{2}$ & $.5620^{* * *}$ & .7246 & $.9769^{* * \star}$ & $.9544^{* * *}$ & $1.05^{* * *}$ \\
\hline$\beta_{3}$ & $-18.38^{* * *}$ & -24.35 & $-30.77^{* * *}$ & $-21.76^{* * *}$ & $-24.04^{* * *}$ \\
\hline$\beta_{4}$ & $-16.14^{\star \star *}$ & -16.21 & $-24.10^{\star \star *}$ & $-20.30^{* * *}$ & $-22.91^{\star * *}$ \\
\hline$\beta_{5}$ & $6.45 \mathrm{E}-50^{\text {**t* }}$ & $-1.74 \mathrm{E}-22$ & $.4 .14 \mathrm{E}-06$ & $.0054^{* * *}$ & -.0004 \\
\hline$\beta_{6}$ & $4.20 \mathrm{E}-51^{+* *}$ & $8.90-18$ & 0.0017 & -0007 & -.0181 \\
\hline$\beta_{7}$ & $-9.10 \mathrm{E}-51$ & $5.24 \mathrm{E} 21$ & $.01966^{* * \prime}$ & -.0127 & -.0177 \\
\hline $\bar{R}$ & .253 & .348 & .303 & .194 & .192 \\
\hline
\end{tabular}


herding behavior, we have used six major cryptocurrencies listed in the CCI30 index. We hypothesized some model to check the herding pattern in cryptocurrencies, which were tested by using quantile regression instead of using normal OLS. The results indicated that in the CKK model,the herding that exists at upper quantile in market may be due at that time to the market moving quite fast and continuously trading, with prevailing bullish trends. Further analysis confirmed this narrative as at upper quantile the beta of bullish regime is negative and significant, meaningthe main source of market herding is bullish trendsin investment, which increase market turbulence and give investors an opportunity to herd. Also, other than market regimes or trends, it is believed that herding can exist in periods of high volatility or low volatility. We used the squared market returns to measure the proxy of market volatility by using 30 days moving averages to generate a high and low volatility period.Results indicate that herding in cryptocurrencies exits in high volatility period, but this herding mainly depends on market activity, not market movement.

We also tried to capture the interdependency and intradependency effects in the cryptocurrency market.For this, we formulated equations vi and vii by keeping in mind Chiang and Zheng (2010). The results indicate that the interdependency effect in sub-major cryptocurrencies by major cryptocurrencies only exists in low-turbulence period because investors try to hedge against weak securities when they are willing to take risk at low level. However, the intradependency effect in major cryptocurrencies by major equity stocks is not observed in theDow-Jones industrial average index;it may be due to tight regulatory setup in equities and the Dow-Jones capability to correct any anomaly that occurs. Maybe other indices show some correlation with cryptocurrencies, which should be considered in future studies.

The reason of herding in crypto market can be linked to its weak regulatory setup (Nadarajah \& Chu, 2017) Moreover, it is a highly speculative and volatile market, meaning any anomaly can create volatility (Li et al., 2014; Ciaian et al, 2014). Investors should try to pay attention to the market trends and related information while taking decision on investment as right now, during current pandemic, the volatility in market has increased and investors have started to sell the securities, which is causing turbulence. Market activity is believed to be the source of herding in cryptocurrencies, which creates bullish trends in market when trading volume increase to aggressive investment from investor (Bikhcandani \& Sharma, 2000). The regulatory setup and a better governance system globally could help in managing this issue of cryptocurrencies.

\section{References}

Avery, B. C., \& Zemsky, P. (1998). Multidimensional Uncertainty and Herd Behavior in Financial Markets. The American Review, 88(4), 724-748.

Bikhchandani, S., \& Sharma, S. (2001). Herd Behavior in Financial Markets. In IMF Staff Papers (Vol. 47). https://doi.org/10.1111/ j.1532-950X.1995.tb01298.x

Bouri, E., Gupta, R., \& Roubaud, D. (2018). Herding behavior in cryptocurrencies. Finance Research Letters, (July), 0-1. https:// doi.org/10.1016/j.frl.2018.07.008

Bouri, E., Molnár, P., Azzi, G., Roubaud, D., \& Hagfors, L. I. (2017). On the hedge and safe haven properties of Bitcoin: Is it really more than a diversifier? Finance Research Letters, 20 , 192-198. https://doi.org/10.1016/j.frl.2016.09.025

Cheah, E. T., \& Fry, J. (2015). Speculative bubbles in Bitcoin markets? An empirical investigation into the fundamental value of Bitcoin. Economics Letters, 130, 32-36. https://doi. org/10.1016/j.econlet.2015.02.029

Chu, J., Chan, S., Nadarajah, S., \& Osterrieder, J. (2017). GARCH Modeling of Cryptocurrencies. Ssrn, (2016), 1-15. https://doi. org/10.2139/ssrn.3047027

Ciaian, P., Rajcaniova, M., \& Kancs, d'Artis. (2016). The economics of BitCoin price formation. Applied Economics, 48(19), 1799-1815. https://doi.org/10.1080/00036846.2015.11 09038

Corbet, S., Lucey, B., \& Yarovaya, L. (2018). Datestamping the Bitcoin and Ethereum bubbles. Finance Research Letters, 26(December 2017), 81-88. https://doi.org/10.1016/j. frl.2017.12.006

Devenow, A., \& Welch, I. (1996). Rational Herding in Financial Economics. European Economic Review, 40(3-5), 603-615. https://doi.org//doi.org/10.1016/0014-2921(95)00073-9

Dyhrberg, A. H. (2016a). Bitcoin, gold and the dollar - A GARCH volatility analysis. Finance Research Letters, 16, 85-92. https:// doi.org/10.1016/j.frl.2015.10.008

Dyhrberg, A. H. (2016b). Hedging capabilities of bitcoin. Is it the virtual gold? Finance Research Letters, 16, 139-144. https:// doi.org/10.1016/j.frl.2015.10.025

Fama, F. E. (1970). Efficient Capital Markets: A Review of Theory and Empirical Work. The Journal of Finance, 25(2), 383-417. https://doi.org/10.1111/j.1540-6261.1970.tb00518.x

Fry, J. (2018). Booms, busts and heavy-tails: The story of Bitcoin and cryptocurrency markets? Economics Letters, 171, 225-229. https://doi.org/10.1016/j.econlet.2018.08.008

Gandal, N., \& Halaburda, H. (2016). Can We Predict the Winner in a Market with Network Effects? Competition in Cryptocurrency Market. Ssrn, 1-21. https://doi.org/10.2139/ssrn.2832836

Jalal, R. N. U. D., Zeb, N., \& Fayyaz, U.E.R. (2019). The Effect of Personality Traits on Employee Job Satisfaction with 
Moderating Role of Islamic Work Ethics. Journal of Asian Finance, Economics and Business, 6(2), 161-171. https://doi. org/doi:10.13106/jafeb.2019.vol6.no2.161

Javaira, Z., \& Hassan, A. (2015). An examination of herding behavior in Pakistani stock market. International Journal of Emerging Markets, 10(3), 474-490. https://doi.org/http:// dx.doi.org/10.1108/IJoEM-07-2011-0064

Katsiampa, P. (2017). Volatility estimation for Bitcoin: A comparison of GARCH models. Economics Letters, 158, 3-6. https://doi.org/10.1016/j.econlet.2017.06.023

Li, X., \& Wang, C. A. (2017). The technology and economic determinants of cryptocurrency exchange rates: The case of Bitcoin. Decision Support Systems, 95, 49-60. https://doi. org/10.1016/j.dss.2016.12.001

Moloney, N. (2010). Regulating the Retail Markets: Law, Policy, and the Financial Crisis. In Current Legal Problems (Vol. 63, pp. 375-447). https://doi.org/10.1093/clp/63.1.375

Nadarajah, S., \& Chu, J. (2017). On the inefficiency of Bitcoin. Economics Letters, 150(August 2010), 6-9. https://doi. org/10.1016/j.econlet.2016.10.033

Nakamoto, S. (2008). Bitcoin: A Peer-to-Peer Electronic Cash System. https://doi.org/10.1007/s10838-008-9062-0

Osterrieder, J., \& Lorenz, J. (2017). a Statistical Risk Assessment of Bitcoin and Its Extreme Tail Behavior. Annals of Financial
Economics, 12(01), 1750003. https://doi.org/10.1142/ s2010495217500038

Panagiotidis, T., Stengos, T., \& Vravosinos, O. (2018). On the determinants of bitcoin returns: A LASSO approach. Finance Research Letters, (March). https://doi.org/10.1016/j. frl.2018.03.016

Polasik, M., Piotrowska, A. I., Wisniewski, T. P., Kotkowski, R., \& Lightfoot, G. (2015). Price fluctuations and the use of bitcoin: An empirical inquiry. International Journal of Electronic Commerce, 20(1), 9-49. https://doi.org/10.1080/10864415.2016.1061413

Pretcher, R. J. R. (2001). Unconscious Herding Behavior as the Psychological Basis of Financial Market Trends and Patterns. The Journal of Psychology and Financial Markets, 2(3), 120125.

Tu, T.-T., \& Liao, C.-W. (2020). Block Trading Based Volatility Forecasting: An Application of VACD-FIGARCH Model. Journal of Asian Finance, Economics and Business, 7(4), 5970. https://doi.org/10.13106/jafeb.2020.vol7.no4.59

Urquhart, A. (2016). The inefficiency of Bitcoin. Economics Letters, 148, 80-82. https://doi.org/10.1016/j.econlet.2016.10.033

Vidal-Tomás, D., Ibáñez, A. M., \& Farinós, J. E. (2018). Herding in the cryptocurrency market: CSSD and CSAD approaches. Finance Research Letters, (July), 1-6. https://doi.org/10.1016/j. frl.2018.09.008 